\title{
The Role of UNICEF's Intervention Programs in Improving Polio Coverage During the Humanitarian Crisis in Yemen
}

\author{
Hanan Saleh, Lucy Sebli-Seidelson
}

To Link this Article: http://dx.doi.org/10.6007/IJARBSS/v11-i2/8403

DOI:10.6007/IJARBSS/v11-i2/8403

Received: 04 January 2021, Revised: 30 January 2021, Accepted: 12 Febuary 2021

Published Online: 27 Febuary 2021

In-Text Citation: (Saleh \& Sebli-Seidelson, 2021)

To Cite this Article: Saleh, H., \& Sebli-Seidelson, L. (2021). The Role of UNICEF's Intervention Programs in Improving Polio Coverage During the Humanitarian Crisis in Yemen. International Journal of Academic Research in Business and Social Sciences, 11(2), 572-586.

Copyright: (C) 2021 The Author(s)

Published by Human Resource Management Academic Research Society (www.hrmars.com)

This article is published under the Creative Commons Attribution (CC BY 4.0) license. Anyone may reproduce, distribute, translate and create derivative works of this article (for both commercial and non-commercial purposes), subject to full attribution to the original publication and authors. The full terms of this license may be seen

at: http://creativecommons.org/licences/by/4.0/legalcode

Vol. 11, No. 2, 2021, Pg. 572 - 586

Full Terms \& Conditions of access and use can be found at http://hrmars.com/index.php/pages/detail/publication-ethics 


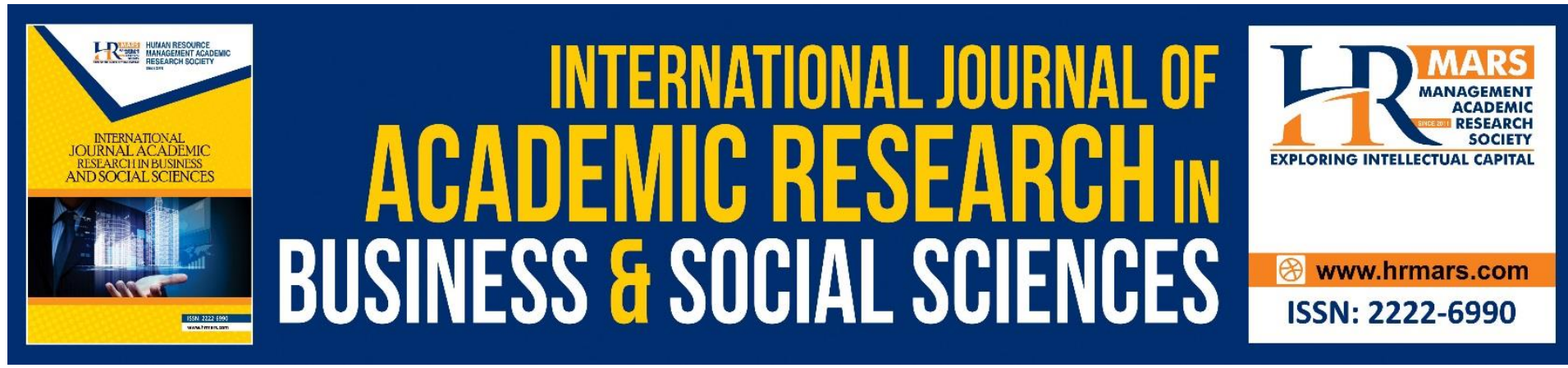

\title{
The Role of UNICEF's Intervention Programs in Improving Polio Coverage During the Humanitarian Crisis in Yemen
}

\author{
Hanan Saleh \\ Postgraduate Student, Department of Political Studies, Faculty of Social Sciences and \\ Humanities, Universiti Malaysia Sarawak, Malaysia \\ Email: hanan.al-jahmi@hotmail.com
}

Lucy Sebli-Seidelson (Ph.D)

Senior Lecturer, Department of Political Studies, Faculty of Social Sciences and Humanities,

Universiti Malaysia Sarawak, Malaysia

Email: slucy@unimas.my

\begin{abstract}
The poor humanitarian situation in Yemen resulted from many factors such as political instability, multiple localized conflicts and chronic underdevelopment. However, when the armed conflict started in March 2015 the whole country started experiencing a great shortage of vaccines which risks the lives of millions of children from infectious diseases such as polio. Therefore, fighting against polio was one of UNICEF's battles in the country. This research aims to provide an assessment regarding the major interventions that UNICEF uses to deliver immunization services including polio vaccines to children during the current humanitarian crisis in the country. The analysis of the results showed that UNICEF's support has a positive impact on children in Yemen. The coverage rate continues to improve slowly despite the challenges faced during the humanitarian crisis. Recommendations to resolve these challenges and to improve the current immunization interventions in the future were proposed.
\end{abstract}

Keywords: Yemen, UNICEF, Humanitarian Interventions, Immunization, Polio

\section{Introduction}

The five years of armed conflict have caused a devastating impact on all fundamental facilities and systems on which the Yemenis have depended upon. The health facilities, the civilian infrastructures and schools have been bombed indiscriminately. Besides, the use of landmines and the recruitment of children in hostile battles forced millions of people to be displaced from their houses which made the humanitarian situation extremely fragile in the country. 
In addition, when the Saudi-led coalition of Arab states began attacking, the whole country became under siege which prevented food and medicines including vaccines and other essential supplies from entering the country. Consequently, the price of basic commodities soared up tremendously while purchasing power declined which affected the standard of living of the majority of the population. Moreover, 16 million people do not have access to clean water and proper sanitation. The fuel is essential to maintain the continuity of the water supply, so the lack of fuel prevented water from being delivered. The limitations on import fuel combined with the damaged water pumping system and sewage treatment facilities have disrupted the water supply in Yemen (OCHA, 2017). This further forces people to use untreated water sources or unprotected wells which put them at risk of life-threatening illnesses such as cholera and acute watery diarrhoea (AWD).

However, since the armed conflict started on the $26^{\text {th }}$ of March 2015, the needs for health care services increased as people in many governorates suffered because access to pivotal services had been cut off. The political conflict and unstable situation caused deterioration in many aspects of the civilians' life, especially in the health sector. The fragile health system faces many critical challenges such as the shortage of medicines, equipment and trained and qualified health staff. With half of the country's health facilities were closed or destroyed, thousands of Yemenis especially children are struggling to get the minimum level of medical help. The children need health services to protect themselves against infectious diseases that can be completely preventable by immunization such as measles and polio.

Polio is a highly infectious viral disease that infects the nervous system in children under five years old especially the new-born. The poliovirus is mainly transmitted through person-toperson due to poor hygiene. Unfortunately, there is no cure for it yet, but it is preventable by immunization. The polio vaccine protects the child for life by giving him/her multiple doses, the children who were affected by polio will require lifelong medical assistance and even wheelchairs to help them during mobility.

However, the armed conflict has almost destroyed all pivotal health infrastructures which indirectly affected access to polio vaccination. This has adversely affected children who are in dire need of polio vaccination. The children are the generation that the country will depend on to re-build the country again after the current crisis is over, therefore they must be protected. This fact forced the international communities to prioritize children when they plan or support any humanitarian interventions in the country.

United Nations Children's Fund (UNICEF) is one of the United Nations' agencies that provides humanitarian and developmental assistance to children and mothers in developing countries including Yemen. Even before the current disaster, UNICEF has many humanitarian interventions in Yemen which focusing on different sectors such as health, nutrition, child protection, education and water, sanitation and hygiene (WASH). One of these interventions is the routine immunization program including polio vaccination which is considered one of the most important health programs that UNICEF and the government are provided to all children in Yemen free of charge. 
The routine immunization program targets the infants in the first month of birth until they reach 18 months old which is when the last dosage will be administered ${ }^{1}$. However, poverty, low awareness rate and the high illiteracy rate among the citizens are considered as major factors that contribute to poor health status among children in rural areas. In addition, those who have limited access to the health care system have to depend on the intervention programs such as the mobile teams (MTs) and outreach (OR) teams to get the vaccinations for their children.

Due to the poor quality of health care services, Yemen's current immunization coverage rate against polio is still far below achieving the acceptable global vaccination coverage rate which is at $85 \%$ (WHO, 2017). According to World Health Organization (WHO) and UNICEF estimates for vaccination coverage in Yemen during 2016, the coverage rate against polio was at $65 \%$, which is a huge drop from the figures that were declared by the ministry of public health and population (MoPHP) which was at 86\% (WHO \& UNICEF, 2018).

\section{Research Problem}

There are many health intervention programs and different practices of immunization in Yemen, which include national campaigns, mobile teams, outreach teams and fixed immunization health facilities. However, there are no such deep studies in the country regarding the efficiency of those practices. With the lack of accurate data, there will always be a research gap in the evaluation system regarding the efficiency of immunization interventions. Therefore, it is important to have accurate data to ensure that immunization interventions work effectively.

Based on the researcher's background in working with polio interventions in Yemen, there is a lack of knowledge regarding the efficiency of health services in the country due to the poor health information system. Moreover, the working international non-governmental organizations (INGOs) -including UNICEF- have almost no authority to collect data directly from the field. Therefore, most of the available and published data are based on estimation.

Furthermore, the absence of independent analysis regarding these interventions at the field level will also limit their efficiency tremendously. Therefore, this study focuses mainly on measuring the effectiveness of these interventions in delivering vaccines to the population in hard-to-reach areas during the current crisis. This study hopes to provide a realistic overview of the major issues faced in remote and rural areas during delivering and receiving immunization service. Finally, the study also attempts to recommend the most appropriate ways to improve polio immunization coverage among children in Yemen as a step to develop the current response system during the emergency in the country.

\footnotetext{
${ }^{1}$ The children receive their first shots of vaccines by given the bacillus Calmette-Guerin (BCG) and oral polio vaccines at the age of one month. Then after six weeks they receive the doses of rotavirus, pentavalent, pneumococcal and oral polio. Those doses are followed after one month by inactivated doses and after another month they are repeated but without rotavirus vaccine. Finally, at age of nine months and 18 months, the measles vaccine and vitamin A are given with doses of oral polio.
} 


\section{Limitations of the Study}

Even before the conflict, there was barely any interest in having an accurate data system in the country. In addition, when the data was collected by the government officers, it was not published electronically. Therefore, most of the data from the government side were either hard to get or outdated. In a similar vein, the data collected by the INGOs are also scarce and very hard to access due to restrictions imposed by the conflicting parties.

In addition, one of the most common challenges facing researchers in Yemen is the bureaucracy system that controls all government institutions. The sharing of internal data with researchers is not allowed without any approvals from the appropriate authorities in the country. Layers of bureaucracy further limit the ability of researchers to pursue their researches as they already have many other obstacles to face such as lack of funding.

\section{Theoretical Framework}

This study will be guided by the extended model of immunization framework that is adopted by UNICEF. This immunization framework was formulated in 2015 by the World Health Assembly (WHA) based on the global vaccine action plan (GVAP). The main purpose of the GVAP is to establish an operational framework to be followed by the INGOs when they implement their immunization interventions over a decade (2011 - 2020). However, in order to enhance the efficiency of immunization interventions, the WHA developed a certain vaccine action plan for each one of the WHO regions ${ }^{2}$. The aim of designing a specific plan for each region is to address the specific needs and challenges that are related to immunization in the countries of that region.

In 2015, the Eastern Mediterranean Vaccine Action Plan (EMVAP) was developed as a framework for the implementation of the GVAP in the countries of that region from 2016 to 2020. To prevent vaccine-preventable diseases, the EMVAP defines the strategic objectives and priority actions of the immunization program with four goals as follows: (1) achieving high routine vaccination coverage by targeting all administrative levels including national and district levels; (2) to meet the elimination target regarding preventable diseases such as measles, maternal and neonatal tetanus and hepatitis $B$; $(3)$ introducing new vaccines for all countries with demonstrated disease burden; and (4) to achieve interruption of wild poliovirus transmission and sustain polio-free status in the targeted country (WHA, 2015).

This study uses that framework model to analyze the efficiency of mobile and outreach teams in improving the polio coverage rate in Yemen. In general, the immunization interventions such as mobile immunization teams are the only opportunity for people in underserved areas to access immunization services. The provision of immunization service through door-to-door and national campaigns could be considered as important resources to raise the coverage rate against polio and to improve children immunity, especially during the current humanitarian crisis in the country.

2 South-East Asia region, Eastern Mediterranean region, African region, European region, Western Pacific region and region of the Americas. 


\section{Review of Literature}

The researcher of the present study reviewed several reports, which related to the impact of the current humanitarian crisis in operating the national health system across the country. In 2016, the MoPHP declared that it is no longer can cover the operating costs and keep providing the population with its services which led to shutting down many of the health facilities in the country (OCHA, 2016). In addition, many of the health facilities were targeted by airstrikes or bombardment causing casualties among health workers, which forced many to leave the country.

This resulted in a lack of health workers, especially in rural areas. The health staff who are still working in the country (although not being paid) are struggling to provide the essential health care services despite the shortages in medicines, essential supplies, power and fuel to power generators. Consequently, many primary health services such as immunization program have been disrupted.

Yemen went through a long struggle to achieve and sustain a polio-free status among its children, especially in remote and rural areas. Before the conflict started in 2015, the immunization against polio had significantly improved when Yemen succeeded to achieve a high immunization rate compared to the past. The coverage rate against polio was $46 \%$ in 1997 and increased to 63\% in 2006 (MoPHP \& CSO, 2015). However, due to the unstable environment in the country since the Arab spring wave in 2011, the coverage rate against polio has decreased to 59\% in 2103 (MoPHP \& CSO, 2015). In addition, the armed conflict in Yemen further exacerbated the already low polio vaccination rate and continued to put a strain on the health system and its workers. As a result, the rate of children who did not receive any kind of vaccinations increased from 12\% in 1997 to $16 \%$ in 2013 (MoPHP \& CSO, 2013).

Similarly, the rate of basic doses against polio also decreased from the second dose to the fourth one (See Figure 1). The deterioration in the national coverage rate and polio's doses rate reflects a failure in the immunization national system in terms of delivering the vaccination regularly and achieving a vaccination coverage rate that closes to the global one which is at $85 \%$.

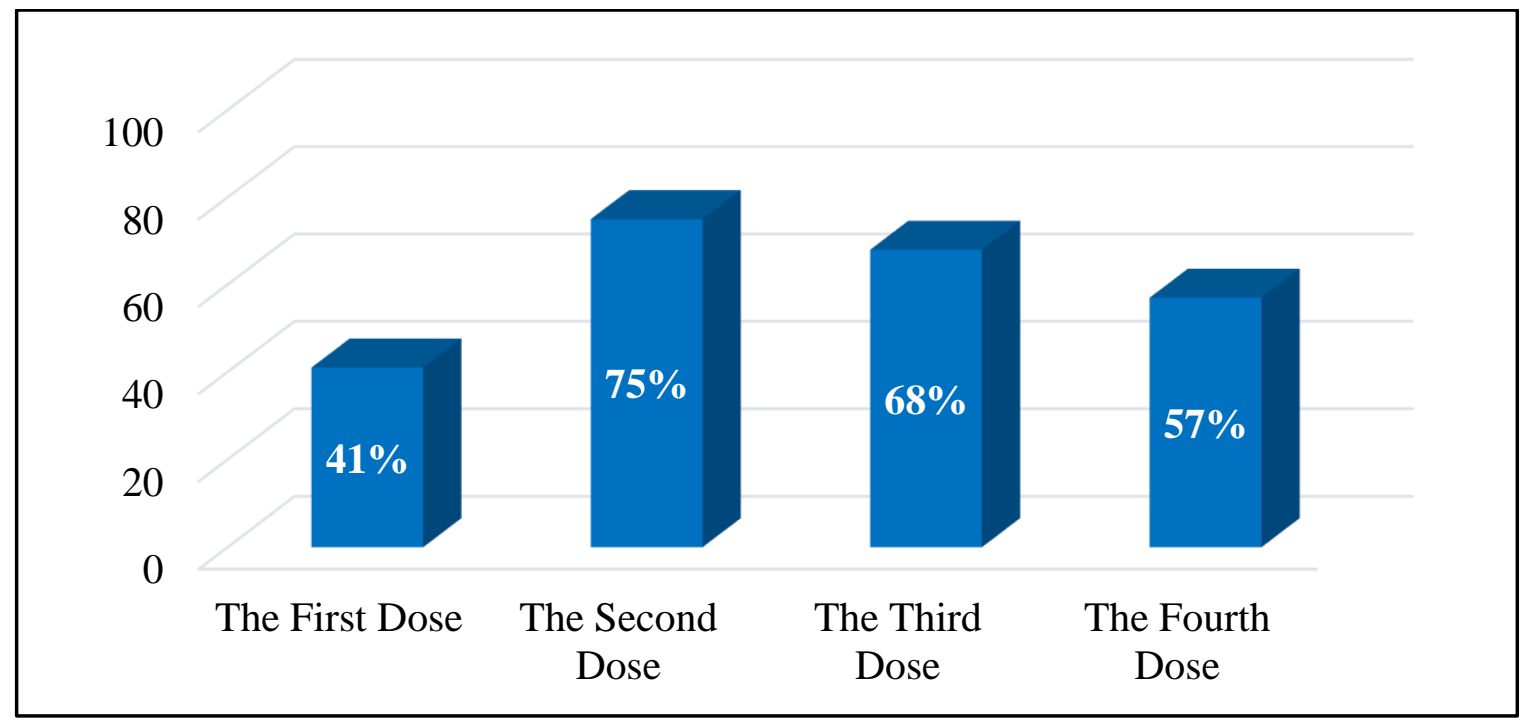

Figure 1: The polio vaccination coverage rate by dose during 2013 (MoPHP \& CSO, 2015) 
Therefore, UNICEF applies mobile and outreach teams in Yemen during the current crisis in order to broaden the geographical coverage by the routine immunization against deadly diseases such as polio. Those teams deliver the vaccines to hard-to-reach areas and among internally displaced persons (IDPs) to ensure that all children are vaccinated. The mobile immunization teams play a key role in raising and maintaining the immunization coverage rate, reducing the inequity in access and preventing more deterioration in immunization coverage against polio in the country (WHO \& UNICEF, 2018).

The health interventions such as mobile and outreach teams are essential activities during emergencies. They are considered as a flexible strategy to deliver the vaccines to the population with limited access to health facilities' locations, especially in rural and remote areas in addition to the IDPs collective shelters. Additionally, mobile immunization teams are the primary source of health education and immunization information for most parents in Yemen. In order to increase demand for immunization, the health workers have to correct the misinformation that the population in those areas have regarding the safety and the effectiveness of polio immunization.

Therefore, the major priority to UNICEF during the current crisis is to support the immunization program as it is one of the most important UNICEF's health interventions in Yemen. The immunization program helps in controlling the spread of communicable diseases such as polio as it provides the future generation in the country with the vaccines that protect them. Hence, the practices that are used to achieve that goal were analysed throughout this study.

\section{The Methodology}

The study aimed to explore the effectiveness of major interventions that UNICEF has used to raise the polio immunization coverage rate. Therefore, the study used quantitative and qualitative research methods. The purpose of choosing mixed methods was to collect accurate data regarding the polio eradication program in Yemen before and during the current conflict.

The quantitative research targeted the household beneficiaries who received immunization services through health facilities or mobile immunization teams. The selection process of those households (HHs) was based on the simple random sample (SRS) method. The researcher picked every second or third $\mathrm{HH}$ inside the health facilities (HFs) to be interviewed until around $1 / 3$ or $1 / 2$ of the required sample had been collected. The reason for choosing the second or third $\mathrm{HH}$ was because of the limited number of available respondents who seeking health services inside the targeted HFs during the researcher's visit days. However, the remaining number of sample size was taken from the catchment areas around the targeted HFs because it was easier to find respondents around the HFs either from the host community or from the IDPs. Therefore, the researcher selected the HH from every fifth, seventh or $10^{\text {th }}$ house either to the right or the left direction of the targeted HFs until the targeted sample size in each targeted district is collected.

On the other hand, the qualitative method focused on collecting data related to the health situation in general and immunization coverage rate specifically in the targeted areas through structured interviews (SIs) with the key informants (KIs) and focus group discussions (FGDs). 
The Sls used snowball sampling with the expanded programme on immunization (EPI) supervisors in the district health offices (DHOs) and the HFs within the targeted areas. There were four SIs with the health facilities management in the four targeted HFs in the centre of each targeted district. Besides, there were four other interviews, two with the EPI supervisors in two DHOs within the four selected districts, and two with the UNICEF's key personnel. The FGDs selection process was also based on a simple random sample (SRS) method. The researcher picked every second or third $\mathrm{HH}$ inside the HFs until a sufficient number of participants (8 - 12 participants) in each FGD is reached.

\section{Study's Units of Analysis}

The study population involved the households (HHs) including IDPs, the management of HFs, the EPI supervisors in the district health offices and UNICEF's key personnel.

\section{Study's Sample}

The sample was taken in Amanat Al-Asimah governorate. Since the beginning of the conflict, 431,000 people were displaced from all other governorates to Amanat Al-Asimah governorate, which made it the most governorate in hosting IDPs (OCHA, 2018). Those IDPs are in urgent needs of humanitarian assistance, especially adequate access to health services. When conducted the data collection at the field level, this massive displacement movement of peoples provided the study with clear diversity that could be considered as a representation for other governorates in Yemen.

As a result, Bani Al-Harith district, Shu'aub district, As Sabain district and Al Wahdah district are chosen. The target sample size is computed to be $362 \mathrm{HHs}$. However, due to the security situation in the targeted areas and the significant financial cost of surveying during the conflict, the researcher used only $30 \%$ of that total number. Table (1) presents such information.

Table 1: The distribution of the sample size in each targeted district in Amanat Al-Asimah governorate (National Information Center, 2004)

\begin{tabular}{|c|l|c|c|c|}
\hline Governorate & \multicolumn{1}{|c|}{ Targeted Districts } & $\begin{array}{c}\text { Population } \\
\text { Size }\end{array}$ & \# of HHs & $\begin{array}{c}\text { The Sample } \\
\text { Size }\end{array}$ \\
\hline \multirow{4}{*}{ Amanat Al-Asimah } & Al Wahdah District & 99,596 & 15,933 & 27 \\
\cline { 2 - 5 } & As Sabain District & 311,203 & 44,730 & 27 \\
\cline { 2 - 5 } & Shu'aub District & 213,939 & 30,293 & 27 \\
\cline { 2 - 5 } & Bani Al-Harith District & 184,509 & 24,345 & 27 \\
\hline
\end{tabular}

\section{Instruments}

The quantitative research focused on collecting data related to the changes that happened in polio vaccination coverage among the targeted beneficiaries in specific areas. The quantitative survey instrument was designed by using open and closed-ended questions techniques interviews regarding socio-demographic characteristics in the targeted areas, the number of vaccinated children, the accessibility to immunization services and the quality of health services received including immunization before and during the conflict. 
On the other hand, the qualitative method focused on collecting data related to the health situation in general and immunization coverage rate specifically in the targeted areas through SIs with the EPI supervisors in the DHOs and the health facilities within the targeted areas. The SIs were conducted to collect the data and statistics regarding the level of polio vaccination rate and the challenges that were faced during the implementation of immunization intervention during the conflict.

Apart from that, the FGDs were also used with a sample of households in order to obtain indepth information regarding the availability of health services, the quality of these services including immunization and the obstacles that they faced to access the immunization service for their children during the conflict.

\section{Analysis}

The results of the primary data sources such as survey, SIs and FGDs were analysed by using the statistical package for the social sciences (SPSS) and by thematic analysis. On the other hand, the secondary data sources such as government statistics and INGOs reports had been analysed by using the thematic descriptive method. The researcher organized the available statistics and reports, then interpreted them in order to provide a rich description regarding these sources.

\section{Findings and Discussion}

In general, the fieldwork showed that immunization interventions have a positive impact on the overall access to immunization services and the targeted beneficiaries' health. However, the research found that there are complex challenges that weaken these interventions and limit the efficiency of their services. The insufficient immunization services in the rural areas, the geographical boundaries, the economic situation and the high cost of transportation to the nearest health facility are regular complications that face the population when they seek health services.

At the same time, the health facilities in the country were continued to be targeted by heavy bombardment and airstrikes. Almost half of the health facilities are no longer functional due to structural damages. Similarly, the health workforce became demotivated to continue working as they stopped receiving their salaries since the outbreak of the conflict, while at the same time, risking their lives every time they went to work.

During the fieldwork, it was found that the insufficient numbers of health workers have impeded access to immunization services for a significant number of targeted respondents, especially in rural areas. The conflict also caused a reduction in the number of trained health workers, trained midwives, mobile immunization teams and national vaccination campaigns. This left the children in these areas at risk of losing the polio-free status in the future.

Incongruent with this, due to the poor economic situation, the poorest and most vulnerable people became more dependent on mobile immunization services. The data analysis showed that $99 \%$ of the respondents said that they depend on public health sources to get immunization services for their children. The public health sources such as public HF and mobile immunization teams are considered as the "main sources" of immunization to these respondents. 
During the SIs with UNICEF's key staff and HFs management, they mentioned that the current conflict and the rugged geographical features in Yemen require specific interventions to deliver immunization to the population who do not have access to the HF in their areas. It was clear that UNICEF and MoPHP identified their priority by supporting interventions that facilitate access to national immunization systems which have been decreased due to political and economic instability in the country. Based on SIs' results, the researcher found that UNICEF supports the immunization program in the HFs by providing operational budget, vaccines, the cold chains and boxes to store these vaccines at proper temperatures. In addition, it was also evident that UNICEF supports these teams with training and monthly incentives to encourage them to keep providing the very much needed routine immunization services, as well as supplied the teams with multiple vaccines and cold boxes to store the vaccines in proper condition.

However, in term of the efficiency of mobile and outreach teams in improving the polio coverage rate in Yemen, the study analysed the HFs' records and UNICEF's reports since the conflict has started. When the analysis was conducted, it is noticed that the immunization coverage rates against polio in the targeted health facilities in Amanat Al-Asimah governorate are far below the estimated rates from UNICEF's reports (See Figure 2).

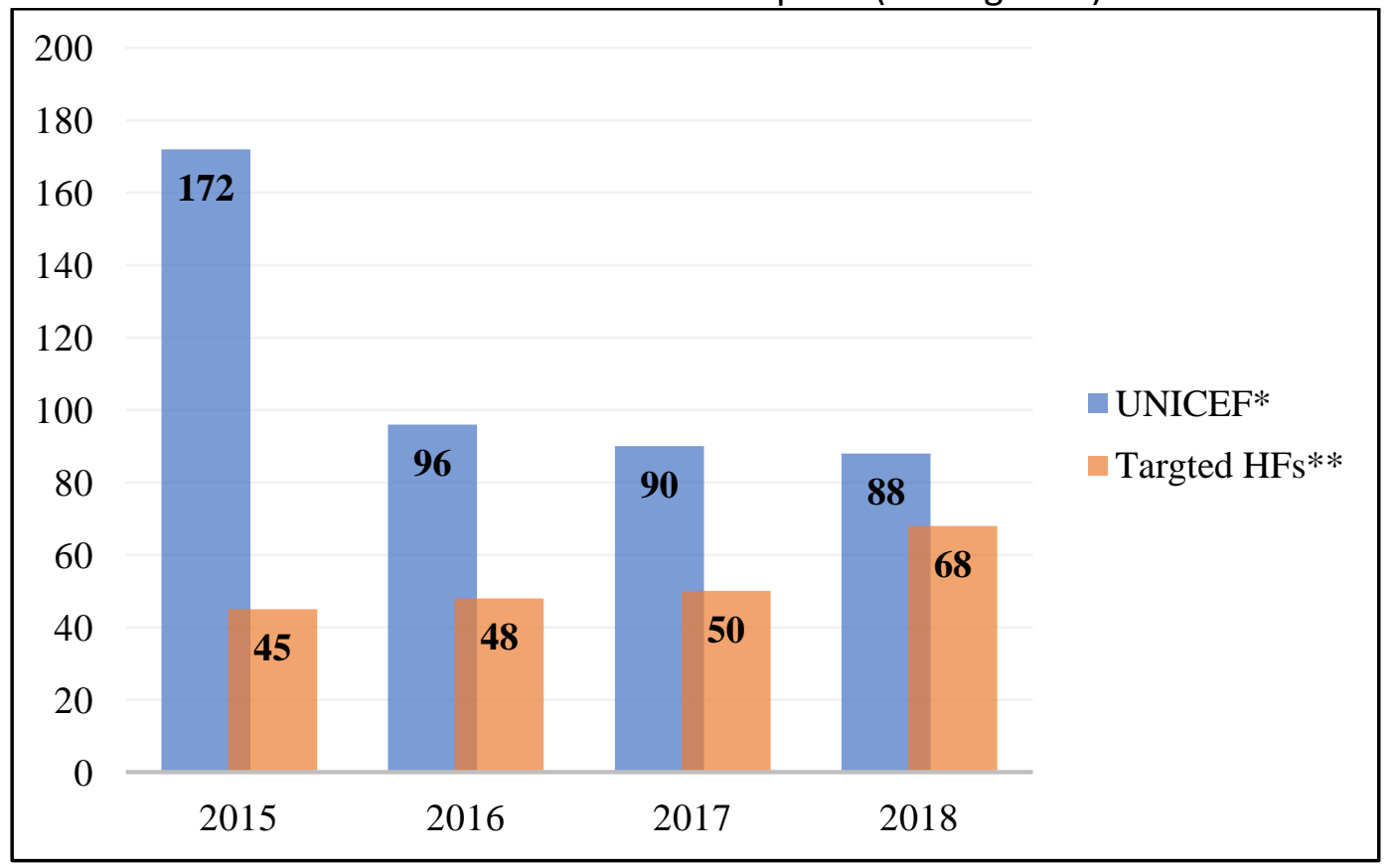

Figure 2: The comparison of polio coverage rate between UNICEF and the targeted HFs in Amanat Al-Asimah governorate (UNICEF, 2015, 2016, 2017, 2018)

In addition, the data collected through the SIs with the HFs' management also revealed that UNICEF only supports these HFs with the operating cost and incentives without paying the health workers' salaries. This has a critical effect which reflected in the respondents' answers during the survey, in which $20 \%$ of the respondents said that they faced regular difficulties to find the health workers in the HF during the operating hours. Correspondingly, $60 \%$ of the respondents stated that they were requested by the health workers to pay a "service fee" to vaccinate their children (See Figure 3). 


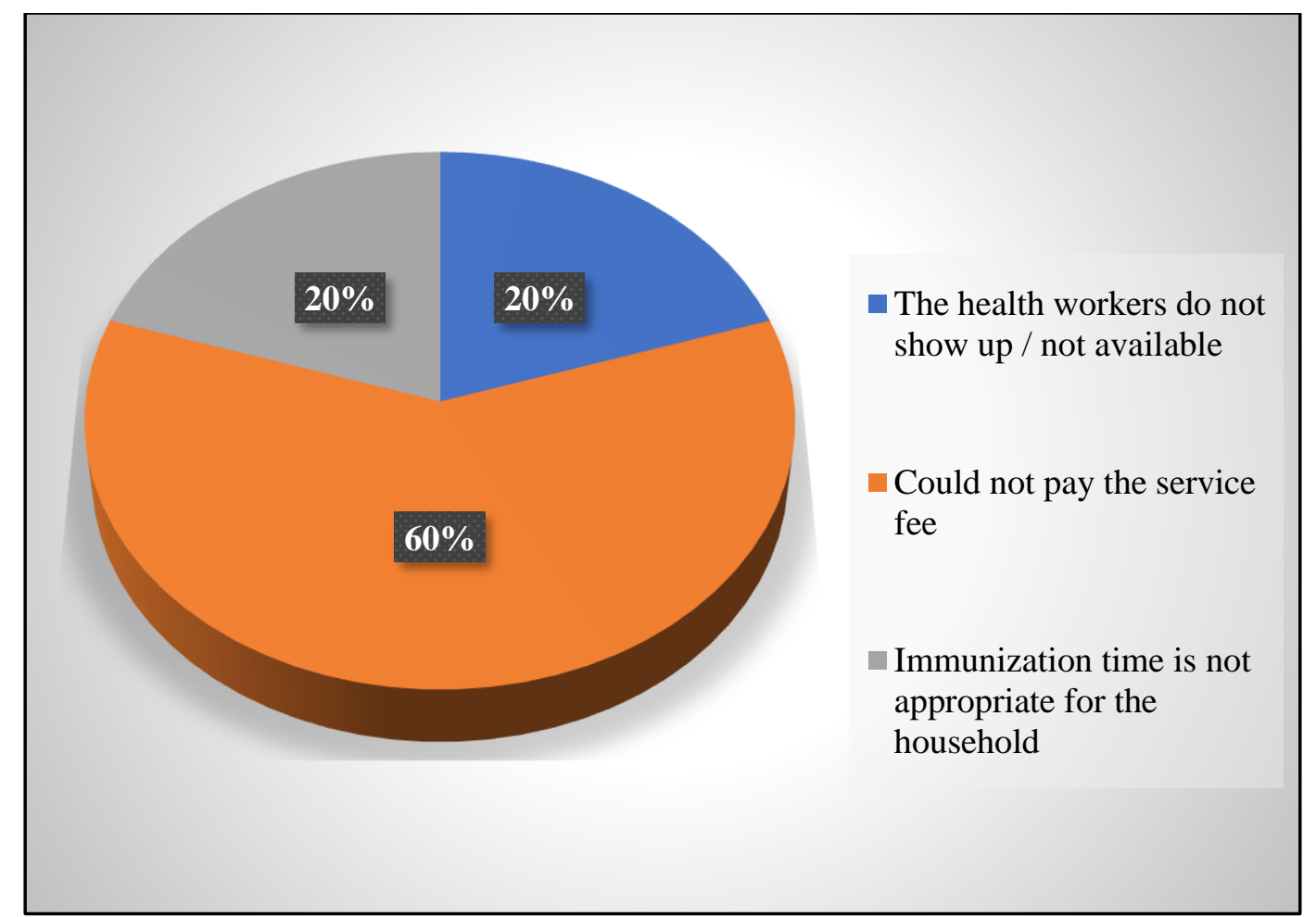

Figure 3: The most common difficulties to get vaccination among the respondents

Regarding the respondents' complaints about the service fee, the health workers in the targeted HFs argued that they have to ask the beneficiaries for a "service fee" as a consequence of MoPHP's failure to pay up their salaries. Consequently, they are forced to look for another source of income even if it was from the beneficiaries' pocket.

On the other hand, in Yemen, the MoPHP considers a child fully immunized against polio if he/she has received four doses or more. However, it was found that $59 \%$ of children received only three doses against polio (MoPHP \& CSO, 2015). Moreover, it was also discovered that there is a lack of access to the HFs to receive the most important dose which is the first one. It was found that the percentage of polio vaccination that given to new-born infants is too low compared to the other doses, which means that this proportion of infants would be at risk of infection until they receive the second dose after six weeks of birth (See Figure 4 for more details). 


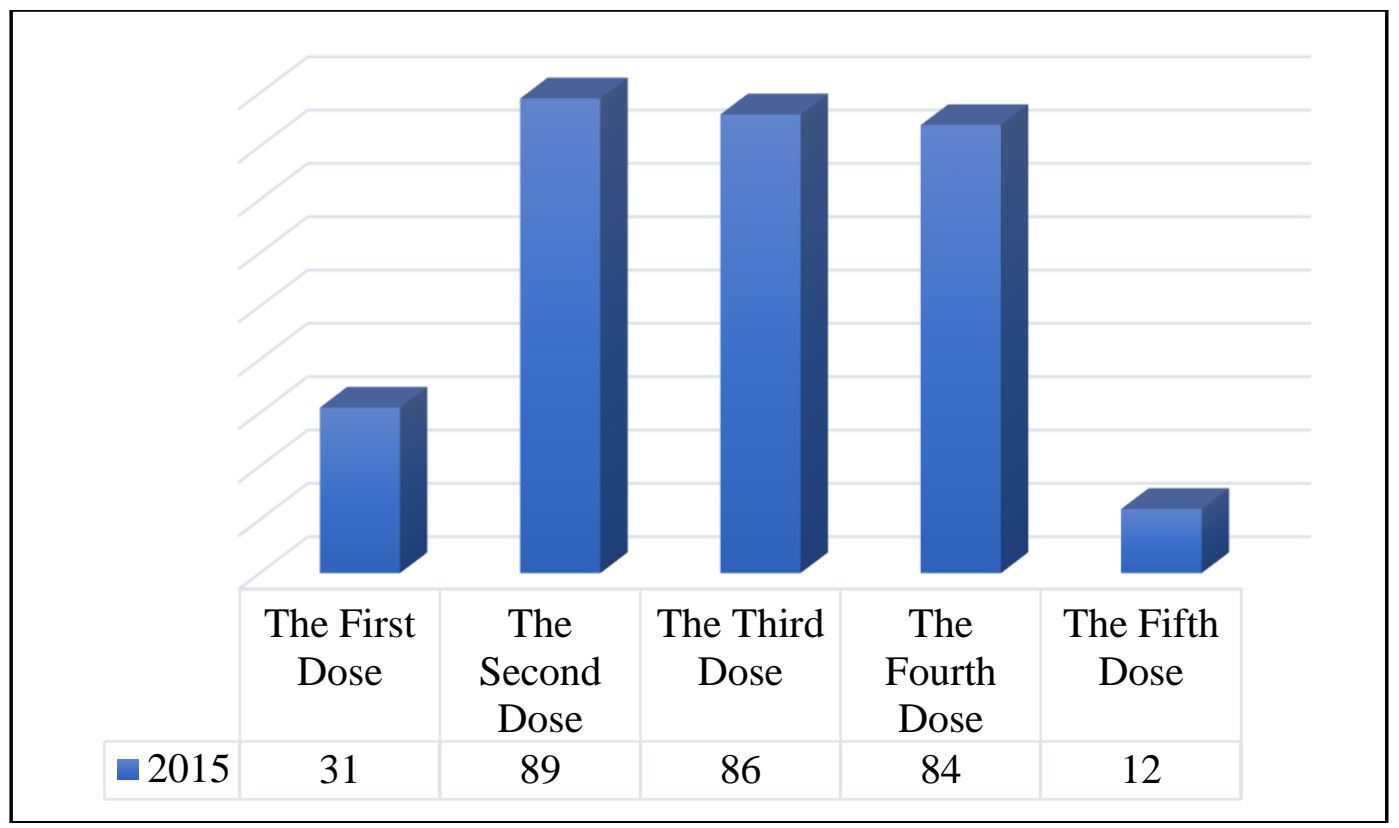

Figure 4: Polio vaccination percentage by dose in Yemen during 2015

Through the FGDs, it was evident that the respondents with limited education were unwilling to complete their children immunization schedule after the third dose due to their perception that their children were already fully immunized against polio. The responsibility of taking the child to immunization often fell on the women's and young girls' shoulders. However, due to the conflict, the road became unsafe for females and the transportation fare became highly expensive. Therefore, the respondents skipped some of the scheduled doses while waiting for the mobile immunization teams to reach their areas instead of going to the public health facility.

Amanat Al-Asimah governorate is one of the worst-affected governorates as a result of the conflict. One of the constraints that faced respondents to access immunization services is the restriction of movement imposed by the fighting parties. Almost $40 \%$ of the respondents stated that their preferable sources to access immunization services were through mobile immunization teams. In the same vein, the mobile immunization services are also popular among slum dwellers, Al-Muhamasheen ${ }^{3}$ and IDPs camps where living conditions have continued to deteriorate further.

The study reveals that the current interventions have faced new logistical challenges and burdens. The massive displaced movement, in addition to the original population, caused more pressure on the health facilities which have limited capacity in medical supplies and health workers. The constant mobility of IDPs and the struggle that beneficiaries have to go through to reach the nearest health facility or immunization delivery points caused immunization drop-out rate either in-between doses or in overall coverage.

These challenges would have a severe impact on the stability of the immunization rate in the long term. Having extensive, organized and reliable data is important to analyse the immunization coverage and to track defaulters on regular basis in order to make informed

\footnotetext{
${ }^{3} \mathrm{Al}$-Muhamasheen is a minority group in Yemen who considered to be at the very bottom of the social rank ladder, mostly they work in menial jobs in the society.
} 
decisions to improve these interventions. It is important to constantly monitor the immunization programme and identify the major system-related issues that affect its performance and develop recommendations to address them.

\section{Conclusion and Recommendations}

In light of the aforementioned results, it was found that there is an essential need for strengthening the immunization system. Therefore, to improve the national immunization program, the de facto government in the northern parts of the country and the internationally recognized government in the southern parts need to improve the health services in the areas under their authority. They need to cooperate with the aid agencies such as UNICEF and establish a clear regulation guide that facilitates the INGOs' work without much delay.

The UNICEF provides financial and technical support to MoPHP which needs to prioritize its current health expenditures to efficiently manage its expansion to support health services including immunization. The MoPHP needs to allocate a larger share of its total spending on immunization services to increase the number of health workers in order to attain the full benefit from the immunization program.

Besides, there is an essential need to maximize the opportunities to access immunization services by supporting interventions that facilitate the delivery of vaccines to children. UNICEF and MoPHP need to provide more opportunities to get targeted children through immunization. Deploying and supporting many mobile medical teams and cover their salaries or possible additional personnel costs such as incentives is a necessary measure to meet the high demand for immunization services to the population who have been cut off.

Research findings also indicated that there is a remarkable decrease in the first dose against polio among new-born infants. The government needs to make extra effort to improve the timeliness of immunization schedule and increase door-to-door visits especially among the children in the low-coverage areas. Therefore, raising the number of trained mobile immunization teams especially in rural and remote areas can strengthen the overall coverage and improve the national immunization programme's performance over time.

Research findings discovered that MoPHP is also facing a monumental challenge regarding the monitoring and evaluation system within the country. The district health centres are supposed to collect the immunization data and send it to MoPHP regularly in order to enable the MoPHP to evaluate the immunization interventions' performance. This is further compounded by the fact that the absence of updated and reliable data as a whole will affect the improvement of the national immunization programme.

Therefore, the study recommends strengthening the immunization information system at all levels; monitoring, evaluation, on-site supervision and disease surveillance. The high-quality disease surveillance accompanied by regular monitoring of immunization progress will ensure that all activities are consistent with the national health plan. It is hoped that the development of an effective monitoring and evaluation plan that analyses the performance of the immunization interventions constantly will identify their weak points and give the decision-makers sufficient time to address them. 
Notwithstanding the challenges and conflicts, the MoPHP and UNICEF have done a good job by providing immunization services in Yemen. However, as the strategies unfold over the years, new challenges will arise and new strategies will be needed.

In general, UNICEF works with MoPHP on raising the levels of routine immunization as it is considered one of the best national defence mechanisms against reinfection of many diseases such as polio. Indeed, that mechanism could not work effectively without evaluating the efficiency of immunization interventions in the country. There is a gap in the evaluation system created by the current humanitarian crisis in the country. Therefore, this study tried to identify the gaps in implementing those interventions and generated recommendations that could improve the mechanisms of similar health interventions during emergencies. The researcher hopes that this study provided a better assessment regarding the major interventions that UNICEF uses to deliver the immunization service including polio vaccines to children during the current humanitarian crisis in Yemen.

\section{Acknowledgement}

The researcher deeply acknowledges and appreciates the financial support through the Zamalah graduate scholarship provided by Universiti Malaysia Sarawak (UNIMAS). The author equally appreciates immensely the helpful comments and suggestions of friends and colleagues, notable among them are Mrs. Marzie Hatef and Dr. Khaled Kulaib.

\section{References}

MoPHP, \& CSO. (2013). Yemen: 2013 National Health and Demographic Survey Key Findings. Retrieved January 5, 2021 from https://dhsprogram.com/pubs/pdf/SR220/SR220English.pdf

MoPHP, \& CSO. (2015). Yemen National Health and Demographic Survey: 2013. Retrieved January 5, 2021 from https://dhsprogram.com/pubs/pdf/FR296/FR296.pdf

National Information Center. (2004). A brief on Amanat Al-Asimah Governorate. [Online]. Available from https://www.yemen-nic.info/gover/amanaa/brife/ [Accessed on $5^{\text {th }}$ January 2021].

OCHA. (2016). Revised: 2016 Yemen Humanitarian Response Plan. Retrieved January 5, 2021 from

https://reliefweb.int/sites/reliefweb.int/files/resources/YHRP_2016_Revision_FINAL _30\%20August\%202016.pdf

OCHA. (2017). Yemen: 2018 Humanitarian Needs Overview. Retrieved January 5, 2021 from https://reliefweb.int/sites/reliefweb.int/files/resources/yemen_humanitarian_needs _overview_hno_2018_20171204_0.pdf

OCHA. (2018). Yemen: 2019 Humanitarian Needs Overview. Retrieved January 5, 2021 from https://reliefweb.int/sites/reliefweb.int/files/resources/2019_Yemen_HNO_FINAL.p df

UNICEF. (2015). Yemen Humanitarian Situation Report. Retrieved January 5, 2021 from https://www.unicef.org/appeals/files/UNICEF_Yemen_Humanitarian_SitRep_29_De c_2015.pdf

UNICEF. (2016). Yemen Humanitarian Situation Report. Retrieved January 5, 2021 from https://www.unicef.org/appeals/files/UNICEF_Yemen_Humanitarian_Situation_Rep ort_Dec_2016.pdf 
UNICEF. (2017). Yemen Humanitarian Situation Report. Retrieved January 5, 2021 from https://www.unicef.org/appeals/files/UNICEF_Yemen_Humanitarian_Situation_Rep ort_Year_End_2017.pdf

UNICEF. (2018). Yemen Humanitarian Situation Report. Retrieved January 5, 2021 from https://www.unicef.org/appeals/files/UNICEF_Yemen_Humanitarian_Situation_Rep ort_Decmber_2018.pdf

WHA. (2015). Eastern Mediterranean Vaccine Action Plan (EMVAP) 2016-2020: A Framework for Implementing of Global Vaccine Action Plan (GVAP). [Online]. Available from http://www.who.int/immunization/global_vaccine_action_plan/eastern_mediterran ean_vaccine_action_plan_2016-2020.pdf?u=1 [Accessed on $5^{\text {th }}$ January 2021].

WHO. (2017). Immunization Coverage: Fact Sheet. [Online]. Available from http://www.who.int/en/news-room/fact-sheets/detail/immunization-coverage [Accessed on $5^{\text {th }}$ January 2021].

WHO, \& UNICEF. (2018). Yemen: WHO and UNICEF estimates of immunization coverage: 2017 revision. Retrieved January 5, 2021 from http://www.who.int/immunization/ monitoring_surveillance/data/yem.pdf 